\title{
A Traveler in God's Path: Sufi Words and the Metaphor of Journey
}

\author{
Sareh Jaberi ${ }^{1}$, Imran Ho Abdullah ${ }^{1} \&$ Ravichandran Vengadasamy ${ }^{1}$ \\ ${ }^{1}$ School of Language Studies and Linguistics, Faculty of Social Sciences and Humanities, University \\ Kebangsaan Malaysia, Malaysia \\ Correspondence: Sareh Jaberi, School of Language Studies and Linguistics, Faculty of Social Sciences and \\ Humanities, University Kebangsaan Malaysia, Malaysia. Tel: 60-18-664-4625. E-mail: sarehjaberi@gmail.com
}

\author{
Received: February 16, 2015 Accepted: May 8, 2015 Online Published: June 13, 2015 \\ doi:10.5539/ass.v11n16p160 URL: http://dx.doi.org/10.5539/ass.v11n16p160
}

\begin{abstract}
Sufi language is a notable style of writing in Persian which is full of novel spiritual ideas and metaphors. One of the widely-used metaphors in Persian Sufis literature is MYSTICAL JOURNEY and its related components such as the traveler in God's path and the notion of God's way. This study is dedicated to analyse the Sufi terminologies in which mysticism has been conceptualized as a JOURNEY metaphor by utilizing a Lakoffian cognitive approach for studying structural metaphors in language. Investigating the MYSTICAL JOURNEY in Sufi language clarifies that the cognitive approach toward metaphors explains the relation between MYSTICISM and the JOURNEY metaphor. The present research attempts to categorize the levels of mapping between the two domains inherent in the JOURNEY metaphor. The paper concludes that there is a rich relation between the two domains in MYSTICISM IS JOURNEY metaphor and by defining the levels of mapping between these two domains, a clearer viewpoint toward mystical metaphors will be achieved.
\end{abstract}

Keywords: levels of mapping, metaphor, mystical Journey, Sufism, the path

\section{Introduction}

The mystical poetry in Iran has been produced for the past twelve centuries and a tremendous amount of mystical literature has been created during this period. Mystical poetry emerged in Iran just 200 years after Islam, coincidently with the rise of the first Sufis, and reached its zenith around the 12th Century. To become a Sufi necessitates the starting of an esoteric Journey toward God who is represented as the ultimate goal of mystical wayfaring. In the meantime, other spiritual progresses were noted as travels on the divine path. Sufi viewpoint toward mystical wayfaring can be traced in their poems and writings which are not restricted to esoteric Journey but the mystical Journey are noted as a key concept of being a Sufi and describes the statues and ideas of Sufism. The process of becoming a Sufi is pervasively conceptualized as a Journey with a starting point, stages and stations, stopping and movement, losing and finding the path, meeting fellow wayfarers and reaching the ultimate goal. In this paper, the linguistic relation between MYSTICISM and JOURNEY is evaluated and a model of relation for structural metaphors is suggested which provides a clearer perception of the borders of mapping between these two concepts.

\subsection{The Background of Mystical Journey Metaphor}

Mystical Journey has a special meaning in Persian culture which is similar to the notion of religious Journey in theological resources. "In the way of God" notion in Persian mysticism is derived from the interpretation fi sabil allah which is used frequently in Qur'an. Martin (2003) points to this Qur'anic interpretation about the Muslim martyrs: "And say not of those slain in God's way, 'They are dead'; rather they are living, but you are not aware (2:154)" (p. 432). Jakel (2002) remarks that focusing on JOURNEY metaphor in religion have advantages in some respects, that are conceptualizing: the idea of a good life, moral choice, hope, the relation between human beings and God, and the most important which is focusing on the PATH schema. The PATH schema has a simple structure that includes a starting point or "a source of motion," the path traversed, and an end point or a goal. PATH schema also implies FORWARD MOTION, PROGRESSING in a "certain DIRECTION", DISTANCE travelled and the SPEED of motion, spatial POINTS and silent LANDMARKS, CROSSROADS or FORKS, and the obstacles that the travellers may be faced with.

Kovecses (2005) remarks that "the god's way" or the moral way is a different mapping of LIFE IS JOURNEY metaphor that characterizes the religious subculture of the western culture. The God's way metaphor is 
represented in the mapping "LEADING A MORAL LIFE IS MAKING A JOURNEY ON GOD'S WAY" (p 125). The worldly and the religious versions of the JOURNEY metaphor have the same mapping:

"Travellers $\rightarrow$ people leading a life

Motion along the way $\rightarrow$ leading a life

Obstacles along the way $\rightarrow$ difficulties in life

Guides along the way $\rightarrow$ helpers or counsellors in life"

The concordance between God's way and LIFE IS JOURNEY metaphor is not perfect. Kovecses points out to the sub-mappings which seem to have a minor role in the religious version of the JOURNEY metaphor:

"Destination(s) of the Journey $\rightarrow$ purpose(s) of life

Different paths to one's destination(s) $\rightarrow$ different means of achieving one's purpose(s)

Distance covered along the way $\rightarrow$ progress made in life

Locations along the way $\rightarrow$ stages in life" (P 126)

Obviously, there is a difference in mapping the Goal between God's way and life's Journey. The biblical religious Journey has no intermediate destinations; there is "only one final goal": the eternal life. In contrary to different ways in life, the straight path in religious Journey is the only way of achieving eternal life. The distance covered and the stages passed in the religious Journey have no correspondence to the "progress made in life". God's way should be passed by an extended effort at all times. In addition to the old biblical version of God's way metaphor, there is also a "third set of mappings" of LIFE IS JOURNEY metaphor in the language of the New Testament. According to Kovecses "a major distinguishing characteristic of this mode of thinking about life is that, in it, the guide of the Journey of life also becomes the way itself" (p. 126).

The framework of a metaphorical relation between an esoteric Journey and a physical Journey in language is well presented in cognitive linguistics (Lakoff \& Johnson, 1980; Lakoff \& Turner, 1989), which focuses on the role of metaphors in perception of an abstract concept and the relation between the components of a linguistic metaphor. Since reviewing mystical words in Sufi texts and encyclopedias will reveal a strong relation between MYSTICISM and JOURNEY, the study of MYSTICISM IS JOURNEY metaphor may be considered as a noteworthy effort to move toward a cognitive survey in Persian mysticism and it presents an analysis of mystical texts as a window to Sufi writing style. Furthermore, it may have some implications for further studies on mystical metaphors.

\section{Structural Metaphors and Conceptual Mapping}

In 1980 a systematic perspective toward metaphor was presented by Lakoff and Johnson in the book Metaphors we live by. Pervious research on cognitive science and cognitive psychology in the late 20th century had accented that the human mind is not a mirror of objective reality but it has some informational structures, which are mediated between the mind's perception and the reality of the outside world (Thagard, 2005). Cognitive linguistics specifically focuses on metaphor function as an instrument for categorizing reality in human mind. As Lakoff and Johnson (1980) assert, metaphor is pervasive in daily life and experiences and the metaphorical system of the mind enables humans to generate metaphorical expressions in language. Metaphor in language is a mapping across two conceptual domains namely the source domain and the target domain. The mapping across lexical units will be able to visualize the conceptual processes, which occurs in the mind's neuronal relations.

Lakoff divided metaphors into three categories, namely orientation, ontological and structural metaphors. Structural metaphors, as Lakoff and Johnson (1980) represent, are the richest relation between two concepts that pervasively organize a target domain in terms of a source domain. This process is conceivable by not only elaborating a concept in details but also via finding appropriate means to highlight some aspects of the target concept and hiding others, as Kovecses (2002) clarifies, in structural metaphor "the source domain provides a relatively rich knowledge structure for the target concept" (p. 37). For example, the structural metaphor MIND IS MACHINE provides a systematic and delineated description for MIND and presents a structural relation between MIND and MACHINE that is beyond a simple similarity between the two concepts, like supposing the human mind as a wired system which has some spaces for data storage and the saving of the data is based on the binary code of 0 and 1 .

Hiding and highlighting is the direct result of structuring a target in terms of a source which prepare a frame to emphasize on some particular aspects of the target and simultaneously hide some other aspects. According to cognitive metaphor theory, the nature of metaphorizing provides a particular point of view for the target concept 
which has been expressed before in Black (1993) as "perspective", in Davidson (1981) as "seeing as" and in Langacker (1987) as the notion of "profiling". Evans and Green (2006) state that structuring ARGUMENT in terms of WAR "highlights the adversarial nature of argument but hides the fact that argument often involves an ordered and organized development of a particular topic" (p. 304).

\subsection{Conceptual Mapping}

The conceptual mapping is the set of correspondences between source domain and target domain. Lakoff and Turner (1989) demonstrate that the general knowledge of domains like JOURNEY is flexible enough to cover the various kinds of Journeys and their components, thus its mapping with LIFE as LIFE IS JOURNEY is open to different interpretations. Different type of Journeys, travellers, ways, destinations, and so on, provides a rich source for different interpretations of life as target domain. Mapping between two domains of a metaphor consists of four elements. Firstly, the schema of JOURNEY has some elements or "slots" that could be optionally filled by the target domain (LIFE).

Table 1. The slots of Journey metaphor

\begin{tabular}{lll}
\hline Journey & Life \\
\hline Traveller & $\longrightarrow$ & A person leading a life \\
Start point & $\longrightarrow$ & Birth \\
Destination & $\longrightarrow$ & Purpose of life \\
Different ways & $\longrightarrow$ & Different lifestyles \\
A path & $\longrightarrow$ & A course of life \\
End of Journey & $\longrightarrow$ & Death \\
\hline
\end{tabular}

Secondly, the relations between elements or slots of a source domain could also be mapped to the relations of slots in a target domain. As Lakoff and Turner remark, the relation between TRAVELLER and DESTINATION gets mapped onto the relation between PERSON and PURPOSE in the target domain. The third and most considerable structure is mapping the properties which involve the mapping of the properties of slots in the source domain onto properties of slots in the target domain. Thus, STRONG TRAVELLER can get mapped onto a person who is strong in dealing with difficulties in his life. The forth structure of mapping is knowledge mapping between domains. By means of knowledge mapping, inference patterns like logical reasoning in source domain get mapped onto target domain. For example, the reasons of metaphorical dead-end in life are directly derived from our knowledge about facing a dead-end in a Journey and trying to find another way. The structure of mapping offers an explicit method for analysing the creative novel metaphors in literary texts. The analysis of mystical language from cognitive linguistics viewpoint sheds light on the metaphorical structure of mystical language as proof of a conceptual mind.

\section{Data Collection}

Table 2. Data collection

\begin{tabular}{|c|c|c|c|}
\hline The word concept & & $\begin{array}{l}\text { Number of the } \\
\text { words }\end{array}$ & \\
\hline Mysticism & \multirow{9}{*}{$\begin{array}{l}\text { Is presented } \\
\text { by }\end{array}$} & 7 words & \multirow{9}{*}{$\begin{array}{l}\text { From the domain } \\
\text { Journey }\end{array}$} \\
\hline The person who starts the mystical method & & 3 words & \\
\hline The path & & 7 words & \\
\hline The obstacles of the mysticism & & 3 words & \\
\hline Starting of mysticism & & 2 words & \\
\hline The goal of mysticism & & 14 words & \\
\hline The guidance of the mystical methods & & 4 words & \\
\hline $\begin{array}{l}\text { Sufis' feeling before reaching the mystical } \\
\text { goal }\end{array}$ & & 3 words & \\
\hline The companions of the mystical methods & & 5 words & \\
\hline
\end{tabular}


The required data for this study were gathered from the book a glossary of Islamic mysticism (Nasr 2011). Investigating the mystical words that are related to the domain of Journey, the glossary of Islamic mysticism is noted word by word and 48 words are detected, whereby some of them are synonyms and these selected words are divided into nine categories of similar words that consist of.

It is worth mentioning that these 48 selected worlds are the common mystical words in mysticism, although some other words in various mystical texts may be placed in the JOURNEY metaphorical domain. Selecting the related words is also limited to a kind of horizontal Journey of "a man on the earth road". Other types of mystical Journeys are excluded such as the vertical mystical Journey to top or high levels, mystical Journey of a fish in the ocean, a bird in the sky or a combination of these types, such as traveling of some birds-as the symbol of the wayfarers-to the top of a mountain such as in mystical poems of Man iq-u - ayr (Farīd ud-Dīn A ār Nishapuri, 1145-1221).

\section{Data Analysis and Discussion}

Conceptualizing mysticism according to a physical Journey seems like a simplification process while mysticism is a vast scope of resources and human historical achievements. Such simplification is indeed the necessity which justifies the use of metaphor in human language and helps the interests to comprehend the intertwined relations of the elements of mysticism. As mentioned in the data collection section, at least nine categories in Sufi texts link the mysticism domain with the domain of physical Journey. For example, there are seven words in Persian Sufi style for the word Mysticism which are related to the domain of Journey.

\subsection{Mysticism Is Journey}

According to the conceptual metaphor theory, metaphorizing MYSTICISM in terms of JOURNEY highlighted some aspects of mysticism and also hides some other aspects. Lakoff et al. (1991) present the "LONGTERM PURPOSEFUL CHANGE IS JOURNEY" as the human mind's underlying metaphor for understanding the complex changes. On this basis, the related metaphors with MYSTICISM IS JOURNEY metaphor originate from a main underlying metaphor level by level.

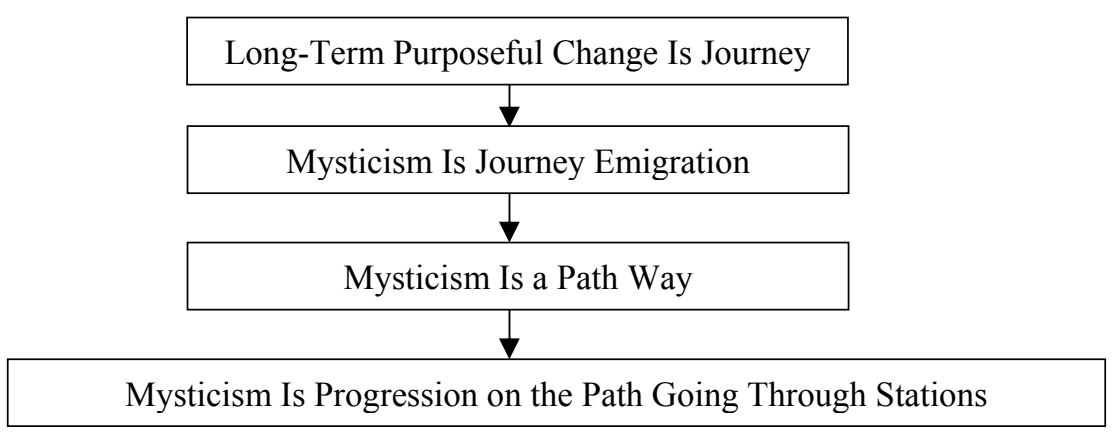

Figure 1.

Each of the above metaphors imposes special features to the notion of mysticism. MYSTICISM IS JOURNEY (سفر) metaphor presents a framework of slots for mysticism that consist of a starting point, an end point, a traveller, a vehicle, a map, the happenings and obstacles during the Journey, etc. MYSTICISM IS EMIGRATION (هجرت) metaphor highlights the importance of the starting and the ending point and figures out mysticism as a fleeing (interpreted as Fleeing to Allah فرار الى اله mysticism as a specific and clear road which needs a traveller and a vehicle and has obstacles. The MYSTICISM IS A PATH metaphor has less emphasis on starting and end point of the mystical Journey. In the meantime, the way itself is really significant with a human character such as a popular quatrain by Attar which says: "start the traveling and ask nothing, the road itself will tell you how you should travel" (p. 86). MYSTICISM IS A WAY (طريقت) has the same features, in addition, it contains the word "method" and MYSTICISM IS A WAY may be interpreted as MYSTICISM IS A METHOD. The third category, MYSTICISM IS PROGRESSION ON THE PATH (سلوك، طى طريق), interestingly highlights the act of traversing the mystical way as in MYSTICISM IS GOING THROUGH STATIONS (طنى منازل) metaphor.

The nearest-to-the-mind slots in metaphorizing mysticism in terms of Journey are the traveler, the path and the obstacles of the way. The person who starts the mystical Journey is called by three names: wayfarer (سالك)), traveler (مسافر), pilgrim (زائر) which is in relation to MYSTICISM IS JOURNEY metaphor. The way or the path

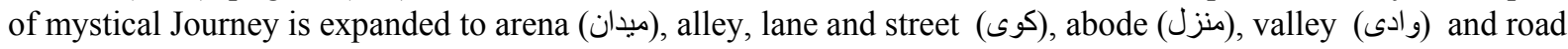


(سبيل), (مقام), lodging (منزلمام). The obstacles of the mystical Journey are dangerous places: pitfall, abyss (ورطن), plain (صحر) and wilderness (بيابان).

The start point of the mystical Journey is an inconvenient location which emphasizes on the motivations of the traveler for starting the Journey and is called Abode of annihilation (دار فانى) and Abode of destruction (خراب آباد). The destination of the mystical Journey could be presented in four categories. In the first category, the destination is a place, world, country, city or home such as Appointment place (ميقات)( ديار (ميقار), Country of friend

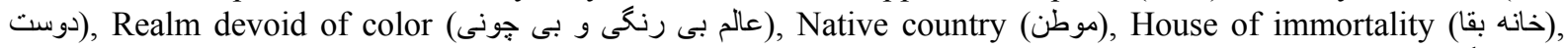

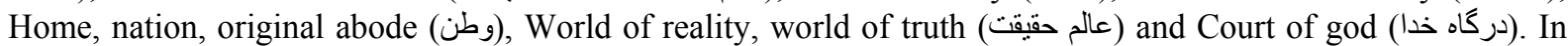
the second category, the destination is a state and experience, such as approach to god (حضرت قرب), approach to God (تقرب به خدا) or proximity (تقرب). The third category simply defines the destination as Arrival and Attainment or reaching the realm of certainty (وصال، اتصال) (وصول به عالم يقين). The forth category is a special interpretation which influences on the linear shape of the mystical Journey from the starting point to the end, that is Return to god (بازكثت به سوى خدا). This latter metaphor changes the image of the mystical Journey from a direct road to a circular shape where the starting point and the end point are the same.
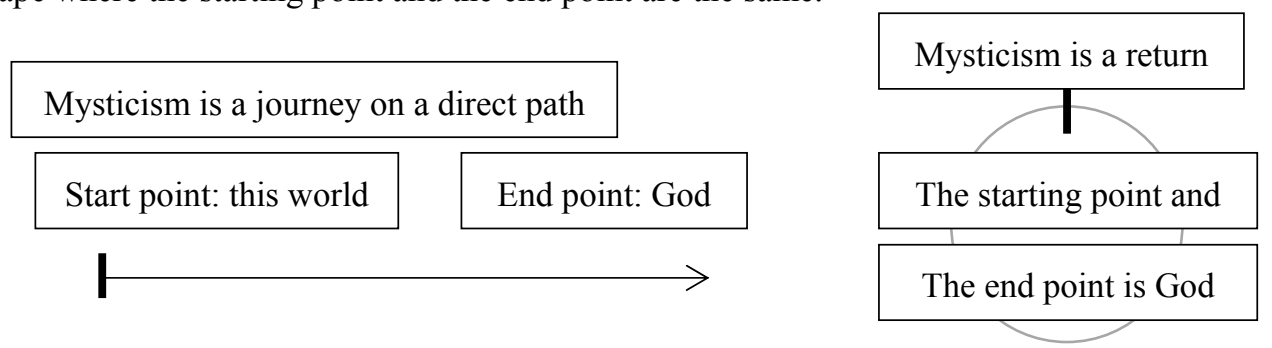

Figure 2. Direct path and return path in mystical Journey

The guide of the mystical Journey is a human, who knows the way, the pitfalls, the wilderness, the destination because he has gone the way once before and is known as the Knower of the path (راه (ر) (ر) (ر) (ر) Road-guide (راهبر). Other guides of the spiritual road may be the lights of guidance (انوار هدايت) and waymarks (راير). The motivation of the wayfarer of the mystical Journey is an inner feeling of exile (غردبر), hardship of separation

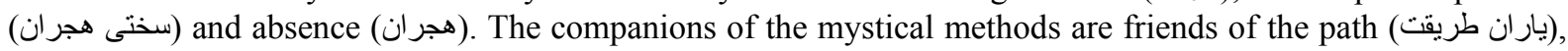

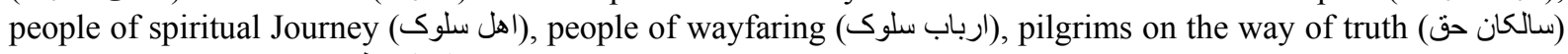
and men of the path (ارباب طريقت).

\subsection{The Mystical Journey Metaphor: Hiding and Highlighting}

Lakoff and Turner (1989) are of the opinion that mapping an abstract concept in terms of a concrete notion is a process which highlights some aspects of the abstract concept. On the other hand, some aspects of the abstract concept are neglected. Therefore, the concrete notion creates a window for watching the abstract concept, where some features are in the frames of the window and some features are hidden because they are out of the frame. However, the relation between the source and target domains is not as simple as the window example. This study suggests that the source domain of a mystical concept develops some levels of hiding and highlighting for the target domain. The following part will propose a four-level method for detecting the relation between the elements of Mysticism and the slots of Journey.

\subsection{The Domains of Mystical Journey: Suggesting the Levels of Mapping}

Conceptualizing an abstract concept via a concrete concept is a way of perception of the intangible and complex concepts, but an abstract notion has various aspects which are not in one-to-one correlation with a tangible physical sense. This means that all aspects of a concrete concept do not participate in the mapping. In other words, as Lakoff and Johnson (1980) mention, a concrete concept has some slots which are not filled by elements of the abstract concept. Table 2 shows that mapping mysticism in terms of a physical Journey is a structural metaphor which structuralizes many aspects of mysticism. However, some slots of a physical Journey do not take part in the mapping and stay silent (i.e. map, luggage and vehicle).

As illustrated in Table 3, the relation between a target and a source domain-as a structural metaphor- seems considerably complicated. To facilitate the classification of various mapped aspects of the MYSTICAL Journey metaphor, a four level categorization is suggested here, which consists of 1) highlighted level, includes those aspects of source and target domains that are in full compliance; 2) semi-highlighted level, that are those components of Journey domain that are similar with their counterpart in mysticism domain; 3) semi-silent level, 
includes some components of Journey domain which do not have an exact equivalent in mysticism domain and the mapping process between them is obscure; and 4) silent level, covering some components of mysticism domain which are not participating in the mapping. The following diagram indicates the levels of connection between Journey and mysticism via conceptual mapping.

Table 3. The slots of mysticism is journey metaphor

\begin{tabular}{ll}
\hline Empty slots of a Journey & Mysticism \\
\hline The traveler & Holy traveler, wayfarer \\
The motivation & Feeling exile and separation \\
Starting point & Perception of annihilation \\
The map of Journey & -a silent slot \\
The luggage & -a silent slot \\
The leader & Knowing man \\
The guidance signs & Waymarks \\
The companions & Men of spiritual Journey \\
The vehicle & -a silent slot \\
The path & The spiritual path \\
The stations & Tranquility union glorification \\
The obstacles & pitfall, abyss, plain and wilderness \\
The destination & God \\
\hline
\end{tabular}

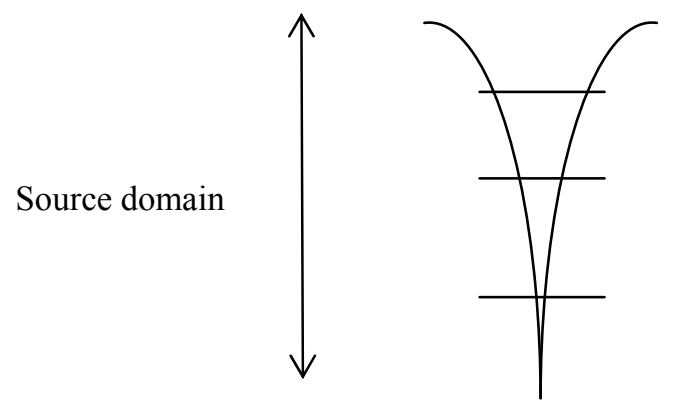

\section{4) Silent level \\ 3) Semi-silent level \\ 2) Semi-highlighted level \\ 1) Highlighted level}

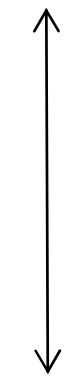

Target domain

Figure 3. The levels of mapping the slots between journey and mysticism domains

In the highlighted level of the mystical journey metaphor are those elements that are shared in the two domains. The one to one correspondence of the components of the source domain and the target domain causes the target domain to be influenced widely by the source domain. These elements seem to be at the center of the metaphor landscape and are crystal clear to the mind. Table 4 displays the highlighted level of the MYSTICAL JOURNEY metaphor.

Table 4. Level 1: The highlighted level of the mystical journey

\begin{tabular}{lllll}
\hline Shared elements & & Source domain: Journey & & Target domain: Mysticism \\
\hline A person & $\longrightarrow$ & Who starts a Journey & $\longrightarrow$ & Who starts a mystical method \\
\hline A person & $\longrightarrow$ & Who is leader of a Journey & $\longrightarrow$ & Who is leader of a mystical method \\
\hline A person & $\longrightarrow$ & Who is companion in a Journey & $\longrightarrow$ & Who does the same mystical method \\
\hline Will and desire & $\longrightarrow$ & For starting a Journey & For starting a mystical method \\
\hline
\end{tabular}

The semi-highlighted level in mapping consists of those elements that belong to another semantic domain. In other words, a physical Journey has an empty slot for the starting point which could be filled with a place or a date but in the mystical Journey metaphor it is filled by a mood, that is, the feeling of exile and separation. When the starting point of a Journey is a mood or a mental state, immediately a question would arise whether it is an inner and mental Journey. In other words, there is an ambiguous connection between elements of the two 
domains which is a sign of the existence of another metaphoric relation. Lakoff et al. (1991) explain that STATES ARE LOCATIONS metaphor justifies the relation between a place in Journey domain and a state in mysticism domain.

Starting point is a place and time for Journey domain $\longrightarrow$ state of annihilation for mysticism domain

The stations are places for Journey domain $\longrightarrow$ permanent mystical states for mysticism domain

The destination is a place and time for Journey domain $\longrightarrow$ state of Approach to god for mysticism domain

The semi-silent level is the third level of correlation between Journey and mysticism that seems to be available because of the power of mapping between two complex concepts. In this level some components of the source domain are repeated in the target domain without any exact evidence. For example, the Waymark-which belongs to the Journey domain-is frequently used in mysticism and the general assumption about the meaning of waymark in mysticism could be anything based on the masters' different spiritual methods. In mysticism, there is no specific meaning for waymark; it presents a frame for anything which can represent a sense of guidance, so it could be a stone or a human or an idea and even something completely different. The other example is "The path" which is a frame for many meanings in mysticism domain with the sense of moving, progressing, developing, advancing and it could consist of many things, many actions and many ideas and interpretations. Concepts such as pitfall, abyss, plain and wilderness are all the same.

In the last level, which is called the silent level here, there are silent slots which are not filled by any element in the target domain such as 'the map', 'the luggage' and 'the vehicle'. The silent slots results in some questions that arise in the mind of wayfarers such as "Is there any map in God's way?" Such questions are often given negative answers by the spiritual masters: "There is no map in this way, this is the way of the unknown" There are many examples in Sufis' spiritual conversations. The hidden level also causes paradoxical phrases about the mystical Journey that are frequently used among the Persian mystics, such as Hafez (1982) "when you travel without feet in God's path" (p. 511), and Molavi (1996) "traveling without feet" (p. 179), "the luggage of no luggage" (p. 1411).

\section{Summary and Conclusion}

The present paper is focused on the mapping of mysticism in Persian mystical language in terms of a Journey. MYSTICAL JOURNEY is a structural metaphor which means that many aspects and components of the source domain get mapped onto the target domain. Conceptualization of a mystical term by means of a tangible notion like Journey causes hiding and highlighting some aspects of the abstract concept. The cognitive theory of metaphor draws a picture of mapping between two concepts that consist of mapping the slots, relations, properties and knowledge. However, the levels of mapping between the two concepts could be visualized in a four-level diagram which provides more accurate details of mapping between the two concepts. The first level includes the best match-up of components of the concepts that are the most highlighted ones in the mapping process. For example, the traveler is a person in the Journey domain and it is also a person in the mysticism domain. The second level consists of similar components but not exactly the same. For example, the starting point in the Journey domain is a date or a place but in the mysticism domain it is a mood or decision. The third level includes those components of the Journey domain that do not have accurate equivalents in the mysticism domain such as 'waymark'. The forth level consists of the silent components of the Journey domain which do not have any equivalents in the mysticism domain. The present study introduced the four-level diagram as an appropriate method for investigating the complicated mystical metaphors in Sufis language and it is hoped that it could provide a window or a framework to the linguistic analysis of mystical metaphors.

\section{References}

Attar, M. (2011). Mokhtarnameh. Tehran, Iran: Sokhan.

Black, M. (1993). More about metaphor. In A. Ortony (Ed.), Metaphor and Thought (pp. 19-41). Cambridge, London: Cambridge University Press. http://dx.doi.org/10.1017/CBO9781139173865.004

Davidson, D. (1981). What metaphors mean. In M. Johnson (Ed.), Philosophical perspectives on metaphor (pp. 31-47). Minneapolis, Minnesota: University of Minnesota Press.

Evans, V., \& Green, M. (2006). Cognitive linguistics: An introduction. Edinburgh, Scotland: Edinburgh University Press.

Hafez, S. M. (1982). The poems of Hafiz Shirazi. Shiraz, Iran: Karavan.

Jakel, O. (2002). Hypotheses revisited: The cognitive theory of metaphor applied to religious texts. Metaphorik de, 2, 20-42. 
Kovecses, Z. (2002). Metaphor: A practical introduction. Oxford, London: Oxford University Press.

Kovecses, Z. (2005). Metaphor in culture: Universality and variation. New York, NY: Cambridge University Press. http://dx.doi.org/10.1017/CBO9780511614408

Lakoff, G., \& Johnson, M. (1980). Metaphors we live by. Chicago, Illinois: University of Chicago press.

Lakoff, G., \& Turner, M. (1989). More than cool reason: A field guide to poetic metaphor. London, England: The university of chicago press. http://dx.doi.org/10.7208/chicago/9780226470986.001.0001

Lakoff, G., Espenson, J., \& Schwartz, A. (1991). Master metaphor list. California, CA: University of California.

Langacker, R. W. (1987). Foundations of cognitive grammar: Theoretical prerequisites. Stanford, CA: Stanford university press.

Martin, R. C. (2003). Encyclopedia of Islam \& the Muslim world. California, US: Granite Hill Publishers.

Molavi, R. (1996). Divan-e-Shams. Tehran, Iran: Karavan.

Nasr, S. H. (2011). A glossary of Islamic mysticism. Tehran, Iran: Suhravardi.

Thagard, P. (2005). Mind: Introduction to cognitive science. London, England: MIT Press.

\section{Copyrights}

Copyright for this article is retained by the author(s), with first publication rights granted to the journal.

This is an open-access article distributed under the terms and conditions of the Creative Commons Attribution license (http://creativecommons.org/licenses/by/3.0/). 